\title{
MECHANISM OF GOSS SECONDARY RECRYSTALLIZATION IN GRAIN ORIENTED SILICON STEEL
}

\author{
J.HARASE*,R.SHIMIZU* and N. TAKAHASHI* \\ *R\&D Laboratories III ,Nippon Steel Corporation,Kitakyushu, \\ Japan,805
}

\section{INTRODUCTION}

Grain oriented silicon steel are mainly produced by two methods. One is the two-stage cold rolling method(1) and the other is the one-stage cold rolling method(2). The two -stage cold rolling method uses mainly MnS as an inhibitor, while the one-stage cold rolling method uses MnS and AlN as inhibitors. Hot rolled sheets containing $\mathrm{MnS}$ as an inhibitor and containing AlN and MnS as inhibitors were processed both by one- stage and two - stage cold rolling method and investigated the effect of inhibitors on the texture evolution by grain growth.

\section{EXPERIMENTAL PROCEDURE}

$2.3 \mathrm{~mm}$ thick hot rolled specimens $\mathrm{A} 1, \mathrm{~A} 2$ and $\mathrm{B} 1, \mathrm{~B} 2$ were processed as shown in Table 1. A1,A2(C:0.04,Si:2.95,Mn:0.09,S:0.026,Al:0.025,N;0.008) are materials for the one - stage cold rolling method.

$\mathrm{B} 1, \mathrm{B2}$ (C:0.04,Si:2.91,Mn:0.08,S:0.029,N;0.003) are materials for the two stage cold rolling method.

Table 1 Experimental procedure

\begin{tabular}{|c|c|c|c|c|c|c|}
\hline Specimen & $\begin{array}{l}\text { Hot band } \\
\text { annealing }\end{array}$ & $\begin{array}{l}\text { Cold } \\
\text { rolling }\end{array}$ & $\begin{array}{l}\text { Intermediate } \\
\text { annealing }\end{array}$ & $\begin{array}{l}\text { Cold } \\
\text { rolling }\end{array}$ & \begin{tabular}{|l|} 
Primary \\
recrystallization \\
annealing
\end{tabular} & $\begin{array}{l}\text { Secondary } \\
\text { recrystallization } \\
\text { annealing }\end{array}$ \\
\hline A 2 & $\begin{array}{c}980^{\circ} \mathrm{C}- \\
120 \mathrm{~s} \\
\text { Air cool }\end{array}$ & $\begin{array}{r}\rightarrow 0.71 \\
\mathrm{~mm}\end{array}$ & $\begin{array}{l}1120^{\circ} \mathrm{C}-120 \mathrm{~s} \\
\text { Boiling water } \\
\text { quench }\end{array}$ & $\begin{array}{r}\rightarrow 0.285 \\
\mathrm{~mm}\end{array}$ & $\begin{array}{l}850^{\circ} \mathrm{C}-150 \mathrm{~s} \\
\text { D.P. } 60^{\mathrm{C}} \\
75 \% \mathrm{H}_{2}-25 \% \mathrm{~N}_{2}\end{array}$ & $\begin{array}{l}1200 \mathrm{C}-20 \mathrm{hr} \\
100 \% \mathrm{H}_{2}\end{array}$ \\
\hline B2 & $\begin{array}{r}980^{\circ} \mathrm{C}- \\
120 \mathrm{~s} \\
\text { Air cool }\end{array}$ & $\begin{array}{r}\rightarrow 0.71 \\
\mathrm{~mm}\end{array}$ & $\begin{array}{l}980^{\circ} \mathrm{C}-120 \mathrm{~s} \\
\text { Air cool }\end{array}$ & $\begin{array}{r}\rightarrow 0.285 \\
\mathrm{~mm}\end{array}$ & Same as above & Same as above \\
\hline A1 & $\begin{array}{l}1120^{\circ} \mathrm{C}- \\
120 \mathrm{~s} \\
\text { Boiling } \\
\text { water } \\
\text { quench }\end{array}$ & & & $\begin{array}{r}\rightarrow 0.285 \\
\mathrm{~mm}\end{array}$ & Same as above & Same as above \\
\hline B1 & $\begin{array}{r}980^{\circ} \mathrm{C}- \\
120 \mathrm{~s} \\
\text { Air cool }\end{array}$ & & & $\begin{array}{r}\rightarrow 0.285 \\
\mathrm{~mm}\end{array}$ & Same as above & Same as above \\
\hline
\end{tabular}


Complete (100)pole figures were measured in the primary recrystallized sheets and B1 after secondary recrystallization annealing, since no secondary recrystallization occurred in B1. They were then inverted by the vector method(3).

The orientations of secondary recrystallized grains(A1,A2,B2) were measured by the back-reflection Laue method.

The relationships between the primary annealed texture and secondary annealed texture was analyzed by the SHG method(4)explained briefly below.

Boundaries in $\Sigma 9$ orientation relationship are more mobile than other boundaries in $\mathrm{Fe}-3 \% \mathrm{Si}$ steel containing $\mathrm{AlN}$ and $\mathrm{MnS}$ as inhibitors(5). In this connection a new simulation method has been developed which uses the intensity of grain orientations measured by the vector method. The coincidence orientation relationships between 1296 representative orientations(which covers $1 / 4$ of the entire orientation space designated by the vector method) are calculated using Brandon's criterion(6). A product $\left(\mathrm{P}_{\mathrm{CN}}=\mathrm{I}_{\mathrm{C}} \Sigma \mathrm{i} \times \mathrm{I}_{\mathrm{N}}\right)$ of the intensity $\left(\mathrm{I}_{\mathrm{C}} \Sigma \mathrm{i}\right)$ of orientations in $\Sigma \mathrm{i}$ coincidence orientation relationship with the intensity of the hypothetical nucleus orientation $\left(\mathrm{I}_{\mathrm{N}}\right)$ are obtained.

\section{EXPERIMENTAL RESULTS}

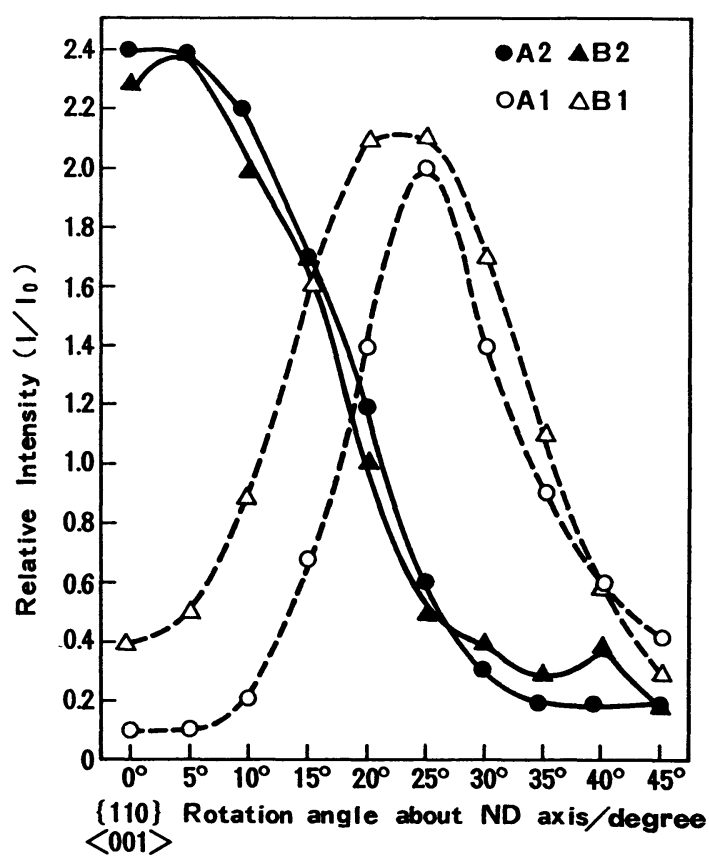

The intensity distribution of the (110)[001] orientation rotated about ND axis in the primary specimens are shown in Fig.1. It shows that the effect of steel type( inhibitors) are very small compared with that of processing methods. Microstructures and orientations after secondary recrystallization annealing are shown in Fig.2. A2\&A1 have larger grain size than that of $\mathrm{B} 2$. No secondary recrystallization occurred in B1. The measured orientations of $\mathrm{A} 1, \mathrm{~A} 2$ and $\mathrm{B} 2$ are classified into 36 Boxes used by the vector method assuming the area of each grain is equal. It shows that the deviation angle of [001] axis from the rolling direction is

Figure 1 Intensities of (110)[001] orientation rotated around ND axis in the primary recrystallized stage. A1,A2:Materials for one-stage cold rolling method. B1,B2: Materials for two- stage cold rolling method.

smallest in A1 and the largest in A2. The Goss orientation is not recognized in $\mathrm{B} 1$. Very large difference in texture between $\mathrm{A} 1$ and $\mathrm{B} 1$ after secondary 
recrystallization annealing can be mainly attributed to the difference of the inhibitor as texture and grain size before secondary recrystallization annealing are similar in both specimens.
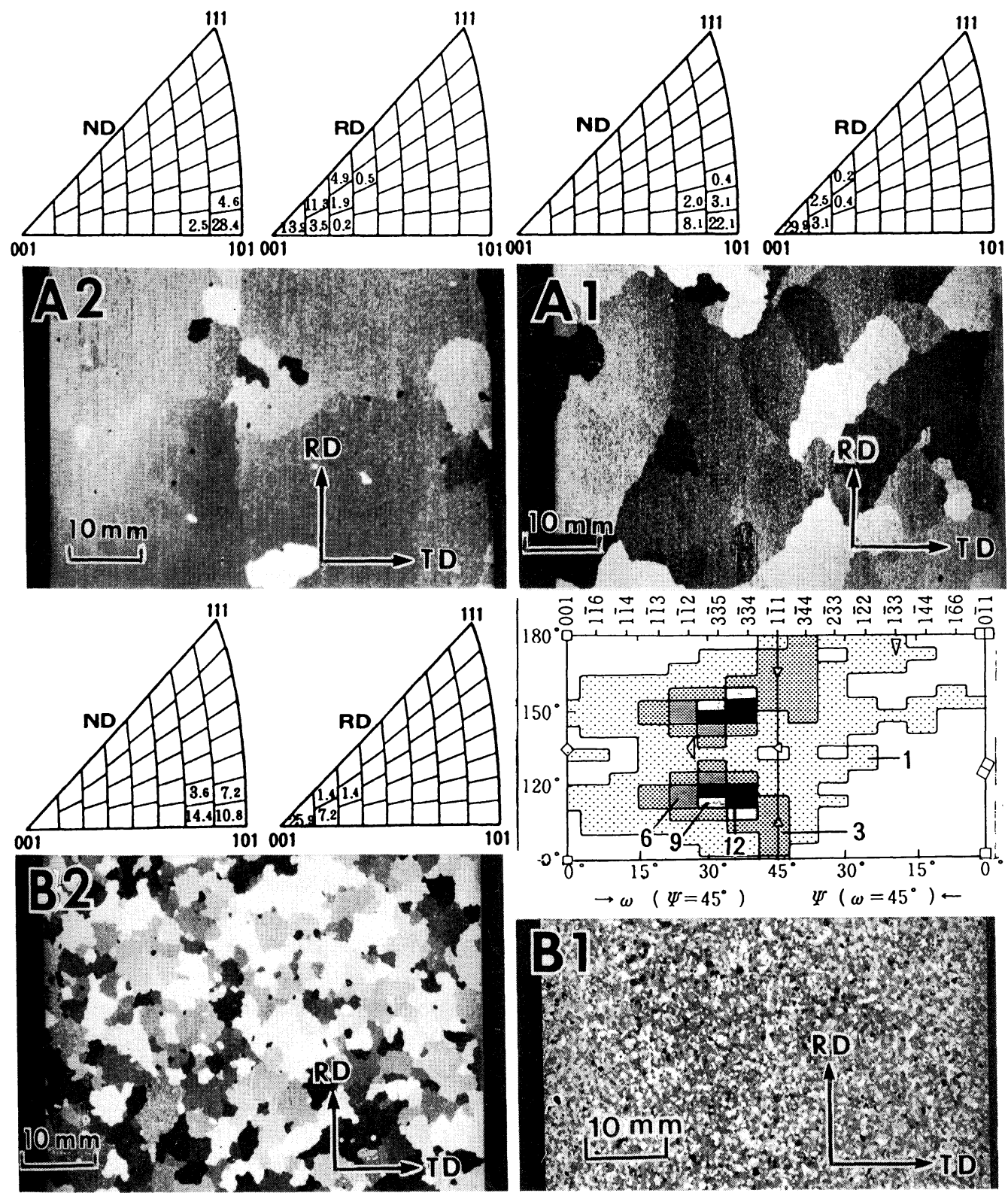

Figure 2 Microstructures and orientations after secondary recrystallization annealing. $\quad \mathrm{A} 1, \mathrm{~A} 2$ : materials for the one - stage cold rolling method(AlN and MnS as inhibitors). B1,B2: materials for the two-stage cold rolling method(MnS alone as an inhibitor). A1,B1: Processed by the one stage cold rolling method. A2,B2:Processed by the two-stage cold rolling method. 


\section{DISCUSSION}

Fig.3(a) shows the frequency of secondary

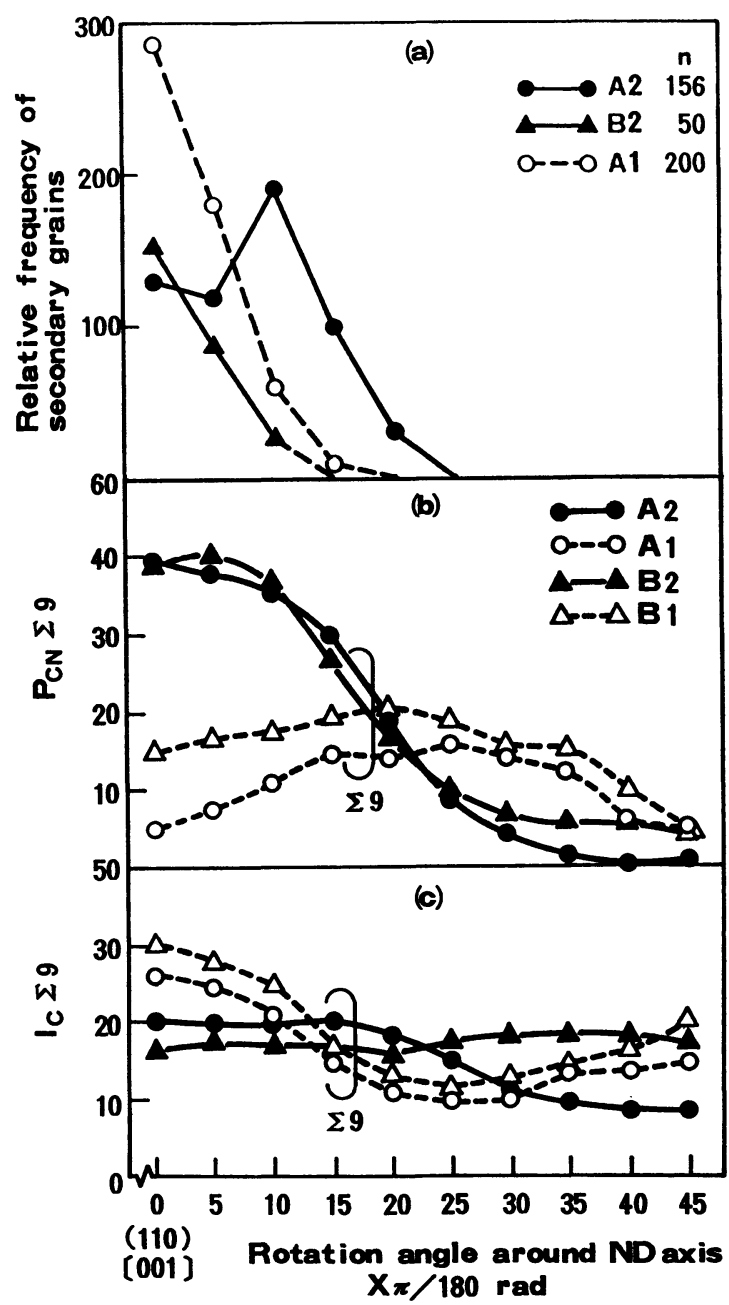

grains classified by the (110)[001] orientation rotated about the ND axis. Fig.3 (b)\&(c) show $\mathrm{P}_{\mathrm{CN}} \Sigma 9$ and $I_{C} \Sigma 9$ values respectively in the primary matrix. Fig.3(a) is not correlated with the $\mathrm{I}_{\mathrm{C}} \Sigma 9$ values shown in Fig.3(c), but is relatively well correlated with the the $P_{C N} \Sigma 9$ values shown in Fig.3(b). The physical meaning of the $\mathrm{P}_{\mathrm{CN}} \Sigma 9$ is a probability of a nucleus orientation coming in contact with $\Sigma 9$ coincidence oriented grains in the matrix. If $\Sigma 9$ coincidence grain boundary is more mobile than other grain boundaries, an orientation with a high $\mathrm{P}_{\mathrm{CN}} \Sigma 9$ value is considered to grow in preference to other orientations. The values of $\mathrm{P}_{\mathrm{CN}} \Sigma 9$ in the two-stage cold rolling method are strongly correlated with the secondary grains as the intensity $\left(I_{N}\right)$ of the nucleus

Figure 3 Relative frequency of secondary grains(a), Intensities of $P_{C N} \Sigma 9$ and $I_{C} \Sigma 9(b \& c)$ of $(110)[001]$ orientations orientation rotated around $N D$ axis in the primary matrix.

orientation is distributed with the ideal Goss orientation as a peak as shown in Fig.2. Fig.3(a) to 3(c) show that $\mathrm{A} 1$ and B1, are similar in the distribution pattern of the $I_{C} \Sigma 9$ values.

The frequency of secondary recrystallized grains in the specimen $A 1$ is relatively well correlated with $I_{C} \Sigma 9$ values.

Secondary recrystallization should occur in B1 if the inhibitor intensity in B1 is same as that of $A 1$ as both specimens have almost the same $I_{C} \Sigma 9$ values. 
This clearly indicates the grain boundary migration characteristics are affected by the inhibitor intensity.

Distributions of $I_{C} \Sigma 9$ and $P_{C N} \Sigma 9$ values in the primary recrystallization specimen $B 1$ are shown in Fig.4. It shows that $P_{C N} \Sigma 9$ values are in close relationship with the texture after grain growth(see Fig.2) and no relationships are found with $\mathrm{I}_{C} \Sigma 9$ values. This suggests that the $\mathrm{P}_{\mathrm{CN}} \Sigma 9$ values are operative on the texture evolved by grain growth when the inhibitor intensity is relatively weak( $\mathrm{MnS}$ alone).

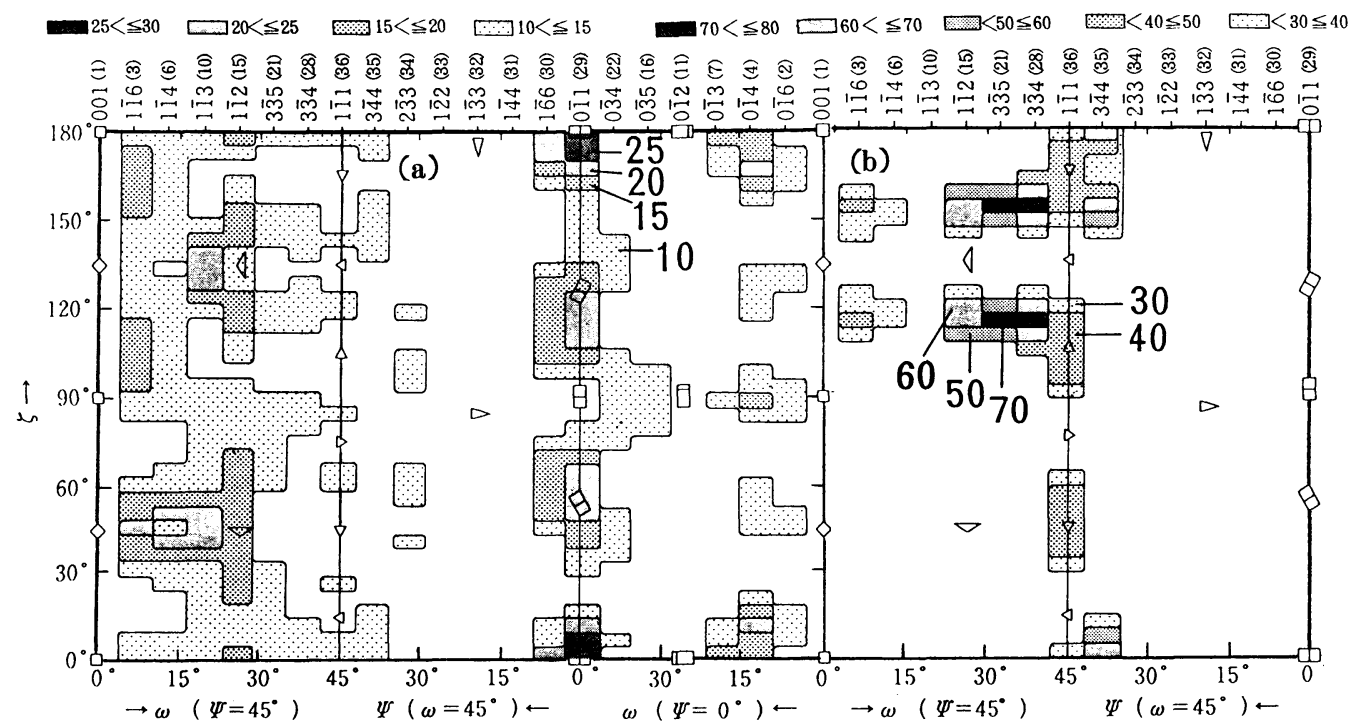

Figure 4 Distribution of $I_{C} \Sigma 9$ values(a) and $P_{C N} \Sigma 9$ values(b) in the central portion of the primary specimen $B 1$.

If $\mathrm{P}_{\mathrm{CN}} \Sigma 9$ values are also operative in $\mathrm{A} 2$, then $\{334\}$ orientations should be one of the major texture components after grain growth as $\mathrm{P}_{\mathrm{CN}} \Sigma$ 9 values of these orientations are high. However, the main texture component after grain growth is Goss orientation as shown in Figs. 3(a).

This contradictory phenomena can be reasonably explained on the assumption that the $\Sigma 1$ boundary inhibition effect varies with inhibitor intensities.

Fig.5(a),(b) show distributions of $\mathrm{P}_{\mathrm{CN}} \Sigma 9$ and $\mathrm{P}_{\mathrm{CN}} \Sigma 1$ values respectively in the primary matrix of the specimen A2. It shows that most of the orientations with $P_{C N} \Sigma 9$ value of 30 or more exhibit $P_{C N} \Sigma 1$ value of 100 or more.

The $P_{C N} \Sigma 9$ value near the Goss orientation alone belongs to a region of 30 or more, where the value of $P_{C N} \Sigma 1$ is less than 100. This means that when the inhibitor intensity is above a certain level, nucleus orientations having high $\mathrm{P}_{\mathrm{CN}} \Sigma 1$ values are inhibited by the $\Sigma 1$ boundaries to grow by increased inhibitor effect of grain boundary migration by $\Sigma 1$ boundaries. Therefore, orientations having high $P_{C N} \Sigma 9$ value s and low $P_{C N} \Sigma 1$ values, namely an ideal Goss orientation in this case, can preferentially grow compared with other orientations. 
This consideration supports the hypothesis that the grain boundary inhibition effect of $\Sigma 1$ boundaries varies with the intensity of the inhibitor.

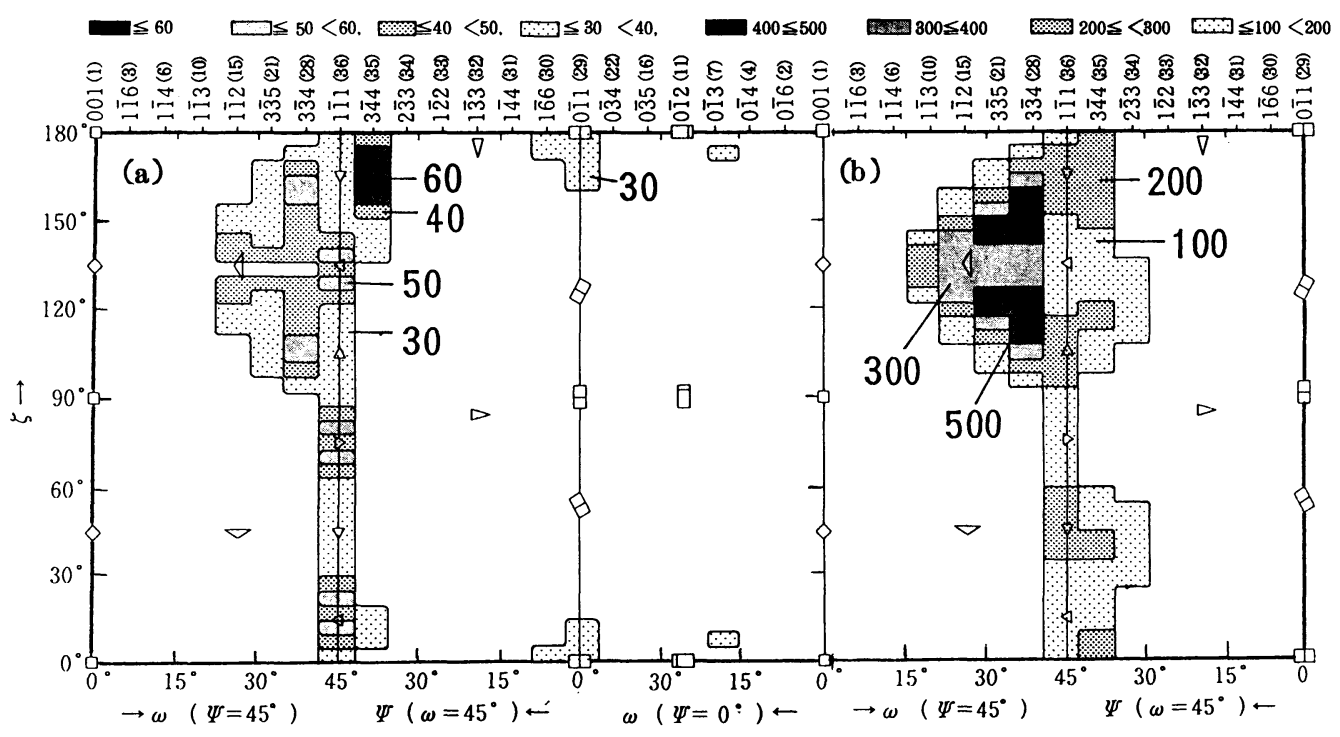

Figure 5 Distribution of $\mathrm{I}_{\mathrm{C}} \Sigma 9$ values(a) and $\mathrm{P}_{\mathrm{CN}} \Sigma 1$ values(b) in the central portion of the primaries specimen A2.

\section{Conclusion}

(1) In the one - stage cold rolling method, $\mathrm{I}_{\mathrm{C}} \Sigma 9$ values are highest in the Goss orientation and $\mathrm{P}_{\mathrm{CN}} \Sigma 9$ values are very high in the $\{334\}<9133>$ orientation in the primary matrix regardless of the materials used. Goss secondary recrystallization takes place when both AlN and MnS are contained and no secondary recrystallization takes place and the texture with the major component of $\{334\}<9133>$ evolves by secondary recrystallization annealing when $\mathrm{MnS}$ alone is contained.

(2) In the two - stage cold rolling method, $\mathrm{P}_{\mathrm{CN}} \Sigma 9$ values are the highest in the Goss orientation in the primary matrix and Goss secondary recrystallization takes place regardless of the materials used.

(3)It is concluded that $I_{C} \Sigma 9$ is operative in the one -stage cold rolling method and $\mathrm{P}_{\mathrm{CN}} \Sigma 9$ is operative in the two-stage cold rolling method for the occurrence of Goss secondary recrystallization.

\section{References}

1.N.P.Goss,Trans.Amer.Soc.Metals,23,511(1935).

2.S.Taguchi,A.Sakakura and H.Takashima, U.S.Patent 3,287,183(1966)

3.D.Ruer,A.Vadon and B.Baro,Texture of Crystalline Solids,3,245(1979)

4.R.Shimizu,J.Harase and D.J.Dingley,Acta Metall.,38,973(1990)

5.J.Harase,R.Shimizu and T.Watanabe,Proc.7th Riso Int.Symp.on Metall. Mater.Sci.,(1986)p.343.

6.D.G.brandon,Acta Metall.,14,1479(1966) 
Textures and Microstructures, 1991, Vols 14-18, pp. 685-690 Reprints available from the publisher

Photocopying permitted by license only
(C) 1991 Gordon and Breach Science Publishers SA Printed in the United Kingdom

RECRYSTALLIZATION TEXTURE FORMATION IN AN ULTRA-LOW C TI-ADDED STEEL WITH $1.5 \%$ SI

NAOMITSU MIZUI* and KURT LÜCKE**

- Sunitono Metal Industries Ltd., Research and Developnent Division 1-3 Nishinagasu-hondori, Anagasaki, 660 Japan.

** Institut fur Allgeneine Metallkunde und Metallphysik in RMTH in Aachen Koperniksstrasse 17, D-5100 Aachen FRD.

1. INTRODUCTION

The mechanism for the recrystallization texture formation based on the orientated nucleation and selective growth theory has been widely accepted. Recently a nucleation mechanism through twinning has been proposed for the dynamic recrystallization of al single crystals / $1 /$. The authors found that ultra-low C Ti-added steels with $1.5 \%$ Si showed a very sharp so called a -fiber cold rolling texture $(<110>/ /$ RD $)$ and a very sharp near $\{554\}<225>$ recrystallization texture at the center layer. The subgrain coalescence mechanism does not seem to be dominant, because there are very few common orientation components between cold rolling and recrystallization textures. Then with a particular emphasis on a nucleation mechanism through twinning, the recrystallization texture formation in ultra-low $\mathrm{C}$ Ti-added steels with $1.5 \% \mathrm{Si}$ is discussed.

2. EXPERIMENTAL PROCEDURE

Ultra-low C Ti-added steels containing $0 \%$ and $1.5 \%$ $\mathrm{Si}$, as given in Table 1 , were melted in vacuum. The $20 \mathrm{~mm}$ thick slabs were soaked at $1573 \mathrm{~K}$ for $1 \mathrm{~h}$, air-cooled to $1323 \mathrm{~K}$, and then hot rolled to $4 \mathrm{~mm}$ thick above $1223 \mathrm{~K}$. 
After hot rolling the hot bands were immediately quenched into water. They were thinned to $2 \mathrm{~mm}$ thick by machining and cold rolled to $0.5 \mathrm{~mm}$ by $75 \%$ reduction. Subsequently they were annealed at $1123 \mathrm{~K}$ for 3 min in a salt bath. $X-$ ray texture analysis was conducted for the central layers of the hot bands, cold rolled and annealed steels.

\begin{tabular}{cccccccccc} 
Table & 1 & \multicolumn{2}{c}{ Chemical composition of steels (in weight } & pct.) \\
\hline No. & C & Si & Mn & P & S & Al & N & Ti \\
\hline A & 0.0005 & $<0.01$ & 0.05 & 0.001 & 0.001 & 0.059 & 0.0033 & 0.078 \\
B & 0.0010 & 1.52 & 0.05 & 0.001 & 0.001 & 0.019 & 0.0027 & 0.071 \\
\hline
\end{tabular}

3. EXPERIMENTAL RESULTS

Figure 1 summarizes the $\{200\}$ pole figures of the hot-rolled, cold-rolled and annealed specimens for both $0 \%$ and 1.5\% Si steels. Although the hot rolling texture of a $0 \%$ Si steel was random, that of a $1.5 \%$ Si steel was a sharp $N D / /<100>$ and $<111>$ texture, which was predicted from the full constrained Taylor model. The texture components developed by cold rolling in $0.0 \% \mathrm{Si}$ steel was both a - and $Y \quad-(<111>/ /$ ND) fibers, which are known as normal cold rolling texture of low $\mathrm{C}$ steels. While in the case of 1.5\% Si steel was a only a -fiber. Latter can be arisen from the hot band structure with elongated grains of $1.5 \%$ Si steel, as calculated with the relaxed Taylor model by Van Houtte /2/. Also there were a large difference between the annealing of them. Those were the full $Y$ fiber and a near $\{554\}<2 \overline{2} 5>$ textures, respectively.

\section{DISCUSSION}

It is well established that a near $\{554\}<2 \overline{2} 5>$ component has the orientation relationship $\{211\}<0 \overline{1} 1>$ in a fiber in the cold rolling texture by $35^{\circ}$ rotation around $<110>$ near normal direction. This orientation relationship results from high angle boundary migration during the grain growth. However the nucleation mechanism of $\{554\}\langle 2 \overline{2} 5\rangle$ is still unclear. Figure 3 shows the $\{200\}$ pole figure, on which the areas with the intensity higher than 1.5 times of random level in both the cold rolling and 

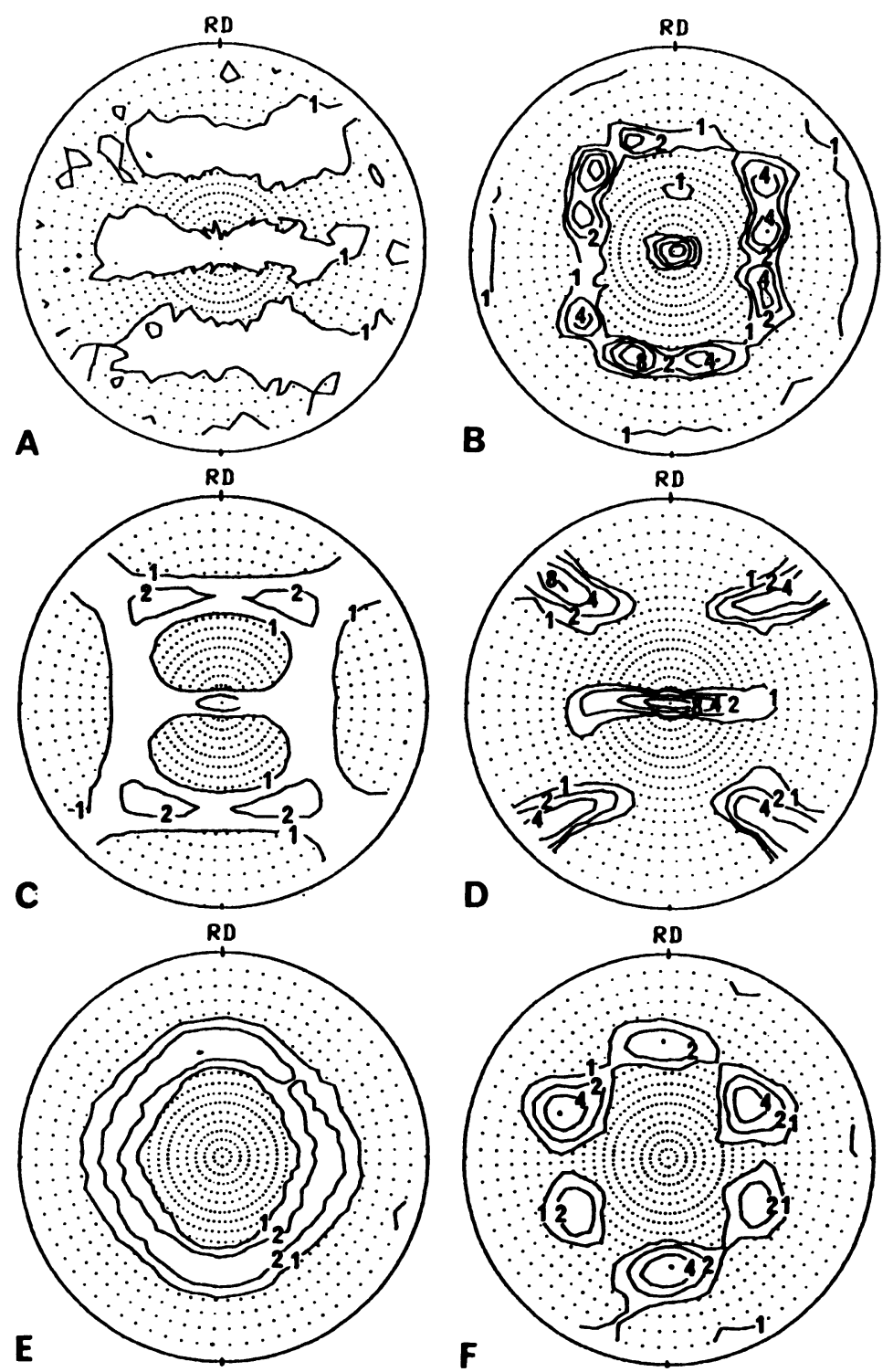

A,C,E: 0.0\%Si steel

B,D,F: $1.5 \%$ Si steel

A,B: Hot band

C,D: Cold rolled sheet

E,F: Annealed sheet

Fig.1 $\{200\}$ pole figure of hot bands, cold rolled sheets and annealed sheets of ulra-low C Ti-added steels containing $0.0 \%$ and $1.5 \% \mathrm{Si}$. 
recrystallization textures are depicted. Because of the lack of common components between both textures, the subgrain coalescence dose not seem to be dominant in the present case. Thus in the following discussion, a new nucleation mechanism will be discussed in order to explain the present result.

Recently it was reported that nucleation occurs through multiple twinning in Al single crystals. In steels with the increase in $\mathrm{Si}$ and the decrese in $\mathrm{C}$, the stacking foukt energy decreses. Therefore in 1.5\% $\mathrm{Si}$ Ti-added steel, the nucleation through twining can be expected. Then with a particular emphasis on a nucleation mechanism through twinning, an analysis was done as in Fig.2.

(1) One major component in the a -fiber was chosen, e.g.

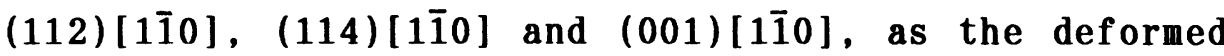
matrix where nuclei grow (Orientations G).

(2) Orientations in the $35^{\circ}$ rotation relation about $\langle 110\rangle$ axes with orientations $G$ were calculated (Orientation $R$ ).

(3) Twin orientations of Orientation $R$ were calculated and checked whether they are in the a-fiber (Orientation $T$ ).

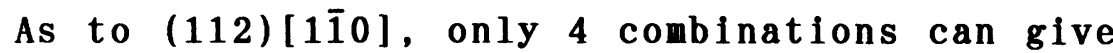
orientation $T$ in the a -fiber, as shown in Table 2 and Fig.3. There are three different rotation paths from orientation $T$ to orientation $R$, because three different twin systems with the same twinning direction give the same Orientation $R$. However in the present result only one of them, that is A in Fig.4, seems to have occurred. Therefore another condition is required.

To consider the activation stress of every twin system, Schmid's factors were calculated for the Tucker stress state, that is, the compressive stress in normal direction and the tensile stress in rolling direction, as shown in Table 2. Then only two combinations are expected to occur. The combination $B$ gives $\{5,3,16\}<12, \overline{4}, \overline{3}\rangle$ recrystallization component. In the case of combination $B$, the orientation $T$ and the orientation $G$ are mirror-symmetric to each other. Therefore the growth probability should be much smaller than that of the combination $A$. 


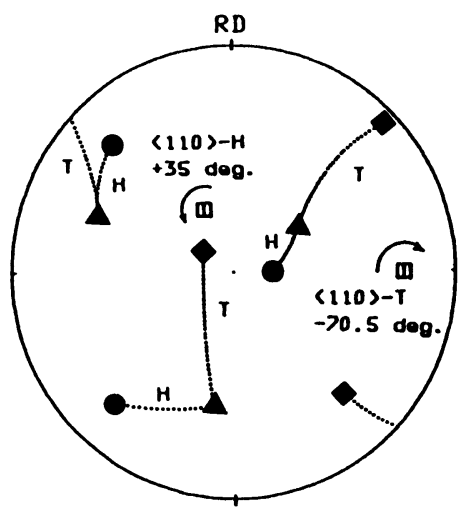

- : Orientation G

: Orientation T

$\Delta$ : Orientation $\mathrm{R}$

Fig.2 Schematic illustration of orientation change through oriented nucleation by twinning and selective growth by high-angle boundary migration.

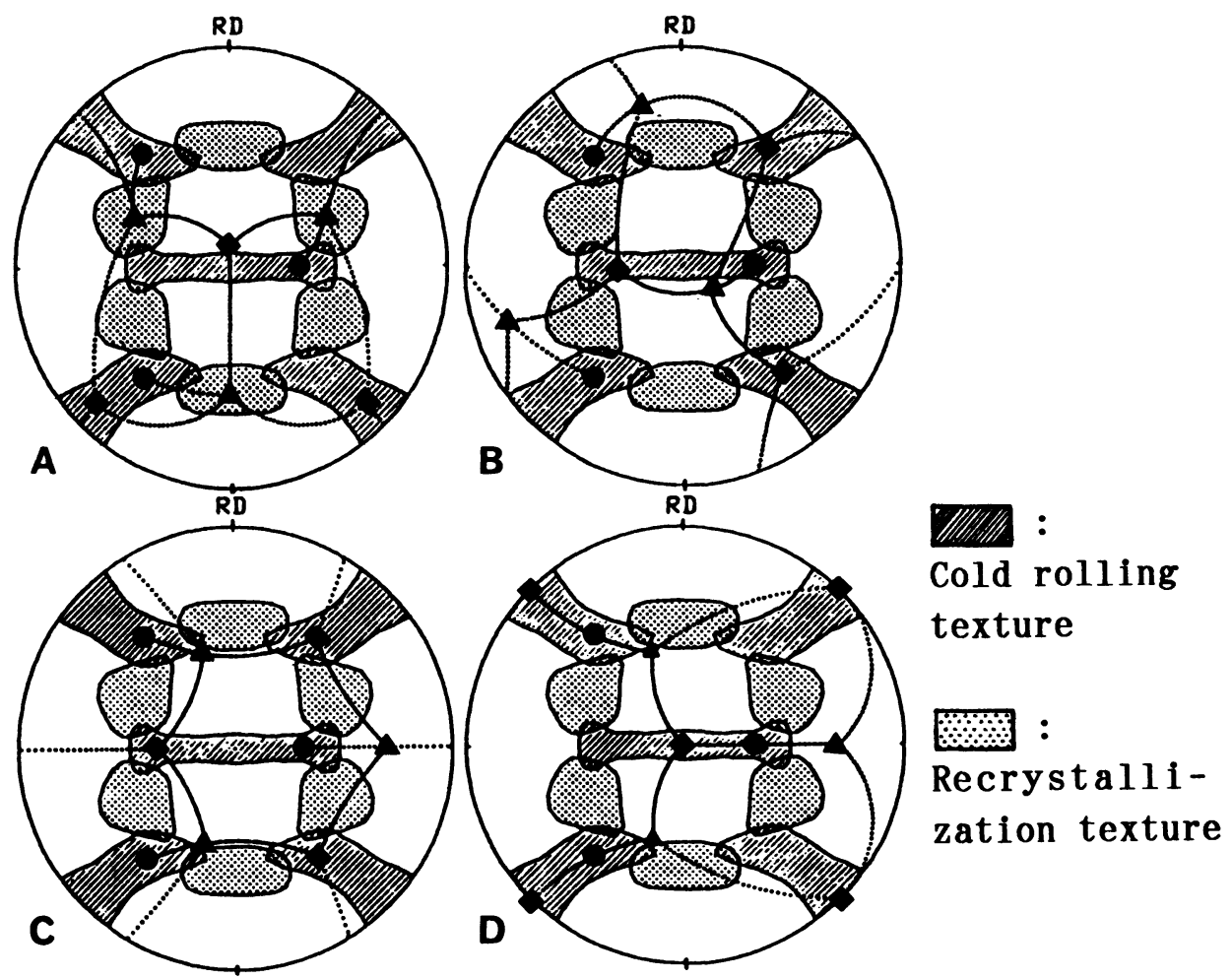

Fig.3 Schematic illustration of nucleation through twinning in one major component in a -fiber cold rolling texture and growth through high-angle boundary migration into (112)[110] cold rolled matrix on co-plotted $\{200\}$ pole figure of cold rolling and recrystallization texture regions with 1.5 times random. (A-D coresponding to A-D in table 2) 
Table 2. Calculation results for (112) [110].

\begin{tabular}{|c|c|c|c|c|}
\hline & $\begin{array}{c}\text { Orientation } \\
T\end{array}$ & $\begin{array}{c}\text { Twin } \\
\text { system }\end{array}$ & $\begin{array}{c}\text { Schmid's } \\
\text { factor }\end{array}$ & $\begin{array}{c}\text { Orientation } \\
\mathrm{R}\end{array}$ \\
\hline A & $\begin{array}{l}(71 \overline{1})[2 \overline{7} 7] \\
\text { near }(100)[0 \overline{1} 1]\end{array}$ & $\begin{array}{l}(2 \overline{1} \overline{1})[111] \\
(\overline{1} 2 \overline{1})[111] \\
(\overline{1} \overline{1} 2)[111]\end{array}$ & $\begin{array}{r}-0.754 \\
0.383 \\
0.372 \\
\end{array}$ & $(545)[2 \overline{5} 2]$ \\
\hline B & $(\overline{1} \overline{1} 2)[1 \overline{1} 0]$ & $\begin{array}{l}(\overline{2} \overline{1} \overline{1})[\overline{1} 11] \\
(12 \overline{1})[\overline{1} 11] \\
(1 \overline{1} \overline{1})[\overline{1} 11]\end{array}$ & $\begin{array}{r}0.112 \\
0.675 \\
-0.787 \\
\end{array}$ & $(5,3,16)[12, \overline{4}, \overline{3}]$ \\
\hline C & $\begin{array}{l}(533)[0 \overline{1} 1] \\
\text { near(211) [0ㅍ1] }\end{array}$ & $\begin{array}{l}(2 \overline{1} \overline{1})[111] \\
(\overline{1} 2 \overline{1})[111] \\
(\overline{1} \overline{1} 2)[111]\end{array}$ & $\begin{array}{r}-0.252 \\
0.126 \\
0.126 \\
\end{array}$ & $(12,2,9)[3 \overline{9} \overline{2}]$ \\
\hline D & $(010)[101]$ & $\begin{array}{l}(2 \overline{1} 1)[11 \overline{1}] \\
(\overline{1} 21)[11 \overline{1}] \\
(\overline{1} \overline{1} \overline{2})[11 \overline{1}]\end{array}$ & $\begin{array}{r}0.236 \\
-0.471 \\
0.236 \\
\end{array}$ & $(12,2,9)[3 \overline{9} \overline{2}]$ \\
\hline
\end{tabular}

5. CONCLUSION

Ultra-low C Ti-added steels with $1.5 \%$ Si were hot rolled in ferritic region and water-quenched immediately. A 1.5\% Si steels showed a sharp a -fiber texture after cold rolling and a near $\{554\}<2 \overline{2} 5>$ texture after subsequent annealing.

The $\{554\}<2 \overline{2} 5>$ component has the $35^{\circ}$ rotation relationship around $<110\rangle$ axes near ND from the near $\{211\}$ $<0 \overline{1} 1>$ cold rolling texture component. However the lack of common components between cold rolling and recrystallization textures suggests that the subgrain coalescence was not the dominant process for the texture formation. Then a new mechanism for recrystallization texture formation was discussed by introducing a new nucleation model through twinning in the deformed matrix. It is concluded that sharp $\{554\}<2 \overline{2} 5\rangle$ recrystallization texture component is nucleated by twinning which occurs in near $\{100\}<0 \overline{1} 1>$ deformed matrix and grows into near $\{211\}<0 \overline{1} 1>$ deformed matrix by high angle boundary migration.

\section{References}

/1/ G.Gottstein et al.: Met.Sci., 13, p223 (1979)

/2/ P.Van Houtte : Proc. ICOTOM-7, p7, Netherlands Soc.

for Mat. Sci., Noordwijkerhout (1984) 